\title{
INVESTIGATION AND OPTIMIZATION OF SURFACE ROUGHNESS AND TOOL WEAR IN DRILLING FOR FE-NI CAST ALLOY BY USING GRA METHOD
}

\author{
Dilraj Chahal \\ Department of Mechanical Engineering \\ HEC Jagadhri, Haryana, India
}

\author{
Shanti Prakash \\ Department of Mechanical Engineering \\ HEC Jagadhri, Haryana, India
}

\begin{abstract}
Cast alloy possess significantly improved properties including high specific strength; specific modulus, damping capacity and good wear resistance compared to other composite metals. Cast Fe-Ni alloy parts by powder metallurgy are important for the industry. These parts are used in many applications that require high strength, hardness and wear resistance. Fe-based alloy produced by powder metallurgy methods are used in camshafts, connecting rods, sprockets, pulleys, various valves, clutch adjustment rings, arm turbine converters, oil pump gears and many applications in the automotive industry. This research is to carried out output parameters like surface roughness and Tool wear during CNC drilling on Fe based alloy with three input parameters; cutting speed, feed rate and point angle. The main objective of the research is to minimize the surface roughness and tool wear after machining with Taguchi and Grey relational method. The data was compiled into MINITAB (® 17 for analysis. The relationship between the machining parameters and the response variables (surface roughness and tool wear) were modelled and analyzed using the Taguchi and Grey relational model. Analysis of Variance (ANOVA) was used to investigate the significance of these parameters on the response variables, and to optimization for the response variables with the machining parameters as the independent variables, with the help of GreyTaguchi relational model. The optimal results for tool wear rate (lower is better) and surface roughness (lower is better) would be achieved when fe-ni alloy work piece is machined at spindle speed of $280 \mathrm{rpm}$, feed rate of $12 \mathrm{in} / \mathrm{mm}$ and depth of cut $1.5 \mathrm{~mm}$. With 99\% confidence interval, optimum value of tool wear rate was found to be $0.049 \mathrm{~mm} 3 / \mathrm{min} \&$ optimum value of surface roughness was found to be $3.04 \mu \mathrm{m}$ respectively.
\end{abstract}

Keywords: Drilling, Fe-based alloy, DOE, ANOVA, Grey Taguchi method, Surface roughness and tool wear.

\section{SAND CASTING}

The Molten Metal is poured in the shaped cavity and then we allow that to solidify in the mould is called as sand casting. We all know that different kind of pattern can be used for the casting. However pattern may be the replica of final product which are going to manufacture with little modifications. These materials are used for moderate, low \& high production measures respectively [3].

\subsection{CAST FE-NI ALLOY}

It is a set of alloys be made up of the elements iron $(\mathrm{Fe})$ and nickel (Ni). This is mainly constituent from the iron meteorites and iron planetary cores. Fe-Ni alloy is corrosion - oxidation -resistant constituents well suitable for service in great situations subjected to heat and pressure. When impassioned, Inconel customs a stable, thick, passivation oxide coating defensive for surface from additional attack [ 44]. This Alloy preserves strength over widespread temperature variety, eyecatching for high temperature submissions wherever steel and aluminum would capitulate to creep as a consequence of thermally tempted crystal positions. Inconel's high temperature power is established by rock-hard solution consolidation or precipitation strengthening, liable on the alloy.

\subsection{DRILLING METHOD:}

Drilling is the basic machining procedure of constructing holes and it is principally for industrialized use like Watch manufacturing industry, aerospace industry, Automobile industry, semiconductors and medical industries. Especially Drilling is necessary in industries for assembly related to mechanical fasteners. The drill is 
called as twist drill, since it has sharp twisted ends shaped around a cylindrical instrument provided with a helical channel along its length to permit the cut and to escape material through it. The sharp ends of conical exteriors crushed at the lower end of rotational twist drill cut the material by shedding it circularly layer by layer when enforced against a work piece. The machined material chips gets curly \& discharge over the helical grooves provided in drill.

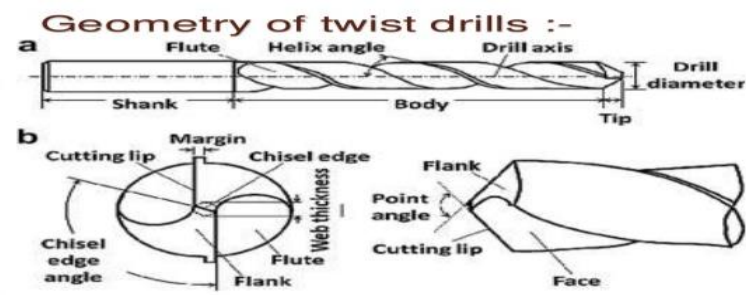

Fig 1.1 Nomenclature of Drill bit

\subsection{TOOL WEAR RATE}

Tool wear in machining is defined as the amount of volume loss of tool material on the contact surface due to the interactions between the tool and work piece. Specifically,

Tool wear is described by wear rate (volume loss per unit area per unit time)

\subsection{SURFACE ROUGHNESS}

The surface finish produced in a machining operation usually deteriorates as the tool wears. This is particularly true for a tool worn by chipping and generally the case for a tool with flank-land wear; although there are circumstances in which a wear land may burnish (polish) the workpiece and produces a good finish.

$$
\mathrm{R}_{\mathrm{a}}=\frac{1}{n} \sum_{i=1}^{n} \mid y_{\mathrm{i}} \text { | }
$$

\subsection{MATERIAL USED}

EN-31 steel is used widely in aerospace, pressure vessels, aircraft turbine and compressor blades and disks, surgical implants etc. Turning is one of the most commonly used machining processes in the shaping of EN-31 steel now days. It has considerable economic importance because it is usually among the finishing steps in the fabrication of industrial mechanical parts.

\subsection{GRA METHOD}

Grey relational analysis method uses an exact model of information as it defines situations through no information as black, and those by way of perfect information as white. In actual situations involvement of these extremes can be described as living being grey, hazy or fuzzy. Therefore, a grey system means that a system in which part of information is known and part of information is unknown. With this definition, information quantity and quality form a continuum from a total lack of information to complete information from black through grey to white. Since uncertainty always exists, one is always somewhere in the middle, somewhere between the extremes, somewhere in the grey area [27].

Grey analysis then comes to a clear set of statements about system solutions. At one extreme, no solution can be defined for any system with no information available. On the other extreme, a system with perfect information has a unique solution. In the middle, grey systems will give a variety of available solutions. Grey analysis does not attempt to find the best solution, but does provide techniques for determining a good solution, an appropriate solution for real world problems.

Let $x_{i}(k)$ is the value of the number $i$ listed project and the number $k$ influence factors.

Usually, three kinds of influence factors are included, they are:

1. Benefit - type factor (the bigger the better),

2. Defect - type (the smaller the better)

3. Medium - type, or nominal-the-best (the nearer to a certain standard value the better).

\section{LITERATURE SURVEY}

Atul A. Bhujugade [2018] in this paper Computer simulation technique and design of experiment used for casting defects analysis. In the first part using casting simulation technique analysis for shrinkage porosity defect is performed and new gating system designed. Number of iteration performed using simulation software to achieve optimum design. With new gating system reduction in shrinkage by (about $2.85 \%$ ) and yield improvement by ( about $9.85 \%$ ) is observed. In the second part DOE used for casting defects analysis so sand related and pouring practices related parameters considered are moisture content, sand particle size, mould hardness and pouring temperature. Taguchi based L9 orthogonal array was used for the experimental purpose and analysis was carried out using Minitab software for analysis of variance (ANOVA).

Rasik A Upadhye (2018) the purpose of this paper is to optimize the sand casting process parameters of the castings manufactured in iron foundry by maximizing the signal to noise ratios and minimizing the noise factors using Taguchi method. A Taguchi approach is used to capture the effects of signal to noise ratio of the 


\section{International Journal of Engineering Applied Sciences and Technology, 2019 \\ Vol. 4, Issue 6, ISSN No. 2455-2143, Pages 150-154 \\ Published Online October 2019 in IJEAST (http://www.ijeast.com)}

experiments depending upon the orthogonal arrays used, an analysis of variance and optimum conditions are found. The results indicated that the selected process parameters significantly affect the casting defects in the foundry. The improvement expected in reduction of casting defects is found to be 37.66 percent.

\section{PROBLEM FORMULATION \& METHODOLOGY}

The objectives of present research are listed below:Keeping all the Literature Gap/Analysis as a primary concern the current study will examine the impacts of various Parameters for "Set up the Iron-based alloy and Drilling with respect to Iron-based alloy material to streamline the response parameters. Further a specialist framework will be created for future expectations of the marvel.

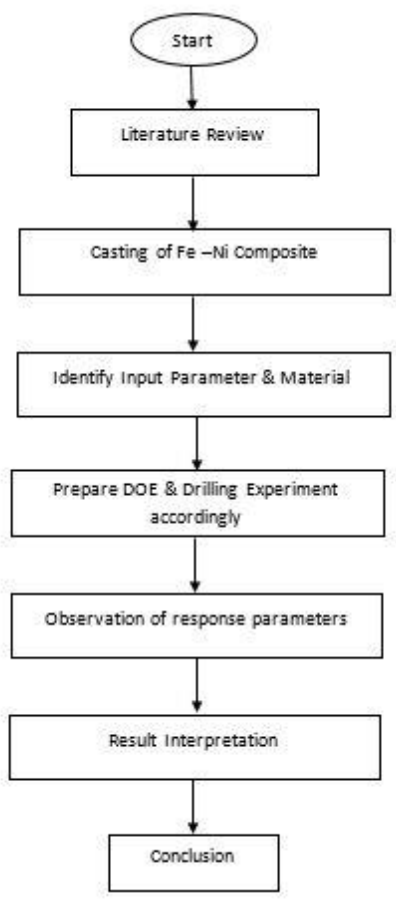

Figure 3.1: Work Plan

\section{EXPERIMENTAL WORK}

Material used for Work piece: cast fe-ni alloy plate is use as work material for this research work. It is a high strength \& corrosive resistant alloy [19]. It has also better strength properties and machinability. The drilling operation done on milling Machining with different parameters.

\subsection{Design of Experiment:}

Designs of experiments are prepared for conducting the experiment.

\begin{tabular}{|c|c|c|c|}
\hline $\begin{array}{c}\text { Exp. } \\
\text { No. }\end{array}$ & $\begin{array}{c}\text { Speed } \\
(\mathbf{r p m})\end{array}$ & $\begin{array}{c}\text { Feed rate } \\
(\mathbf{m m} / \mathbf{m i n})\end{array}$ & $\begin{array}{c}\text { Depth of } \\
\text { cut(mm) }\end{array}$ \\
\hline 1 & 280 & 10 & 1 \\
\hline 2 & 280 & 12 & 1.5 \\
\hline 3 & 280 & 14 & 2 \\
\hline 4 & 340 & 10 & 2 \\
\hline 5 & 340 & 12 & 1 \\
\hline 6 & 340 & 14 & 1.5 \\
\hline 7 & 450 & 10 & 1.5 \\
\hline 8 & 450 & 12 & 2 \\
\hline 9 & 450 & 14 & 1 \\
\hline
\end{tabular}

Table No: 4.1 DOE

Main Effect Plots:

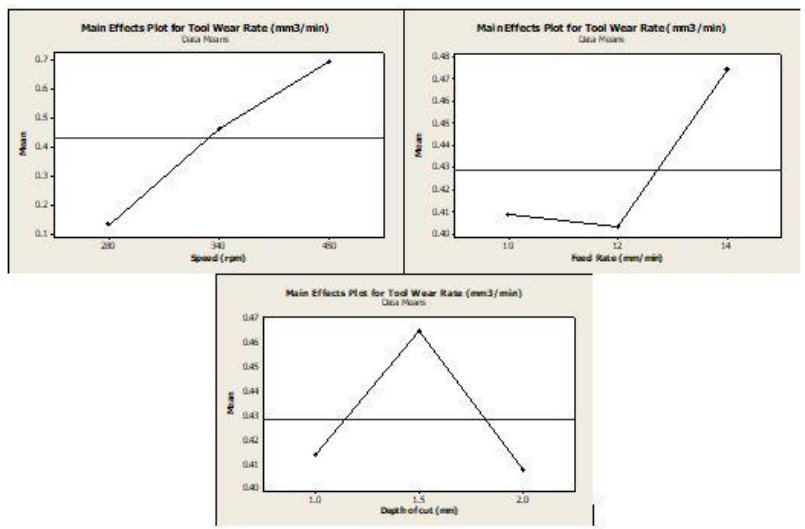

Figure: 4.1 TWR

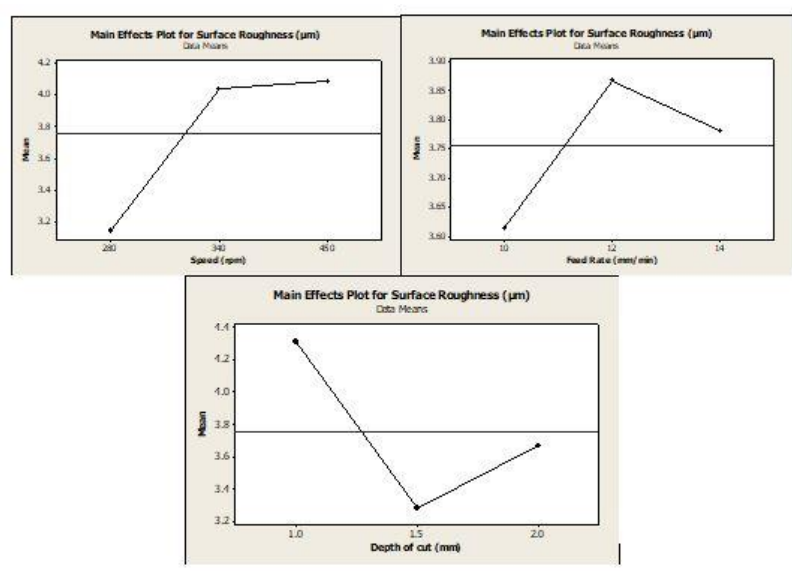

Figure: 4.2 SR 


\section{International Journal of Engineering Applied Sciences and Technology, 2019 \\ Vol. 4, Issue 6, ISSN No. 2455-2143, Pages 150-154 \\ Published Online October 2019 in IJEAST (http://www.ijeast.com)}

\begin{tabular}{|c|c|c|c|c|c|}
\hline $\begin{array}{c}\text { Exp. } \\
\text { No. }\end{array}$ & Speed & $\begin{array}{c}\text { Feed } \\
\text { rate }\end{array}$ & $\begin{array}{c}\text { Depth } \\
\text { of cut }\end{array}$ & TWR & SR \\
\hline 1 & 280 & 10 & 1 & 0.099 & 4.133 \\
\hline 2 & 280 & 12 & 1.5 & 0.087 & 2.570 \\
\hline 3 & 280 & 14 & 2 & 0.211 & 2.733 \\
\hline 4 & 340 & 10 & 2 & 0.365 & 3.597 \\
\hline 5 & 340 & 12 & 1 & 0.476 & 4.350 \\
\hline 6 & 340 & 14 & 1.5 & 0.546 & 4.157 \\
\hline 7 & 450 & 10 & 1.5 & 0.762 & 3.113 \\
\hline 8 & 450 & 12 & 2 & 0.647 & 4.683 \\
\hline 9 & 450 & 14 & 1 & 0.666 & 4.453 \\
\hline
\end{tabular}

Table No: 4.2 Output parameters

\begin{tabular}{|c|c|c|c|c|c|}
\hline $\begin{array}{c}\text { Exp. } \\
\text { No. }\end{array}$ & Speed & $\begin{array}{c}\text { Feed } \\
\text { rate }\end{array}$ & $\begin{array}{c}\text { Depth } \\
\text { ff cut }\end{array}$ & $\begin{array}{c}\text { GRA } \\
\text { Coefficient }\end{array}$ & Rank \\
\hline 1 & 280 & 10 & 1 & 0.684 & 3 \\
\hline 2 & 280 & 12 & 1.5 & 1.000 & 1 \\
\hline 3 & 280 & 14 & 2 & 0.807 & 2 \\
\hline 4 & 340 & 10 & 2 & 0.531 & 4 \\
\hline 5 & 340 & 12 & 1 & 0.420 & 6 \\
\hline 6 & 340 & 14 & 1.5 & 0.413 & 7 \\
\hline 7 & 450 & 10 & 1.5 & 0.497 & 5 \\
\hline 8 & 450 & 12 & 2 & 0.355 & 9 \\
\hline 9 & 450 & 14 & 1 & 0.364 & 8 \\
\hline
\end{tabular}

Table 4.3: Result for GRA Coefficient \& Rank

\subsection{Predicting Optimum performance at their levels}

To compute the optimal output characterstics for Cutting Speed and Torque by using the relation: Predicted Mean $=\mathrm{N}+(\mathrm{A} 1-\mathrm{N})+(\mathrm{B} 2-\mathrm{N})+(\mathrm{C} 2-\mathrm{N})$ Here, $\mathrm{N}=$ Total mean of output individualities (TWR and SR). levels. $\mathrm{n}=$ number of design constraints that effect quality characteristic.

$$
\begin{aligned}
& \text { Predicting Mean Tool Wear } \\
& \quad=0.429+(0.132-0.429)+(0.403-0.429)+ \\
& \quad(0.372-0.429) \\
& =0.049 \mathrm{~mm} 3 / \mathrm{min} . \\
& \text { Predicting SR } \\
& \quad=3.754+(3.145-3.754)+(3.867-3.754)+ \\
& \quad(3.540-3.754) \\
& =3.04 \mu \mathrm{m}
\end{aligned}
$$

\section{CONCLUSION}

The present study was agreed to study the consequence of input parameters on wear rate of tool \& surface roughness. The following inferences have been strained from the experiment:

1. The TWR is generally affected by the feed rate, cutting speed but depth of cut is originate to be a nonsignificant factor during machining and finally come to the conclusion that optimum value of tool wear rate was came at $0.049 \mathrm{~mm}^{3} / \mathrm{min}$

2. The SR is affected by all the input parameters i.e cutting speed, feed rate, and depth of cut. The conclusion for SR is that the optimum value of $\mathrm{SR}$ is found to be $3.04 \mu \mathrm{m}$

\section{REFERENCES}

[1] Atul A. Bhujugade,Vijay B. Sabnis "Minimization of Casting Defects Using Casting Simulation Technique and Casting Defects Analysis Using Design of Experiment" International Journal for Research in Applied Science \& Engineering Technology, Volume 3 Issue VI, pp.722-727-(2018)

[2] Rasik A Upadhye "Optimization of Sand Casting Process Parameter Using Taguchi Method in Foundry" International Journal for Research in Applied Science \& Engineering Technology, Volume 1 Issue VII, pp.1-11(2018)

[3] Rong-Tai Yang1, Hsin-Te Liao1, Yung-Kuang Yang1, Show-Shyan Lin, "Modeling and Optimization in Precise Boring Processes for Aluminum Alloy 6061T6 Components" International Journal of Precision Engineering and Manufacturing, Volume-13, No-1, PP (11-16) (2018)

[4] Jarrah, Al., Jawdat A. and Qahsi, Al., Deya, A. "Optimization of tungsten inert gas welding Parameters for Joining Aluminum Alloys Using RSM", Adv. Theor. Appl. Mech., Vol. 6, pp. 1, 13 -26 (2018)

[5] Sang-An Ha, Jin Sung Lee, Dong Kyun Kim and Jei Pil Wang "Corrosion behavior of Inconel 600 


\section{International Journal of Engineering Applied Sciences and Technology, 2019 \\ Vol. 4, Issue 6, ISSN No. 2455-2143, Pages 150-154 \\ Published Online October 2019 in IJEAST (http://www.ijeast.com)}

Ni-based alloy" International Journal of Applied Engineering Research, Vol.12, pp.4023-4028 (2018)

[6] Fatih Senbabaoglu, Ismail Lazoglu, Salih O. Ozkeser, "Experimental analysis of boring process on automotive engine cylinders" International Journal Advance Manufacture Technology, Volume:48, No:9, PP (11-21) (2017)

[7] Surinder Pal, Ajay Gupta and Rahul Kapoor "Analysis and Validation of Sand Casting Process Using Procast" Journal of Basic and Applied Engineering Research Volume 2, Number 4, pp. 278-281 (2017)

[8] M. Koilraj, Sundareswaran, V. and Koteswara Rao, S.R. "Tunsten inert gaswelding of dissimilar aluminum alloys AA2219 to AA5083 optimization of process parameters using Taguchi technique" Journal of Materials and design, Vol. 42, pp. 1-7 (2016)

[9] Elatharasan, G. and Senthil kumar, V.S. "An experimental analysis and process parameter on Tunsten inert gas welding of AA 6061 - T6 aluminum alloy using RSM" Procedia Engineering, Vol. 64, pp. 1227-1234 (2016)

[10] Tamilselvan, Raguraj, "Optimization of Process Parameter of Drilling in Ti- Tib composite using Taguchi Technique”, ISSN: 2321-5747, Vol.2, No.4 (2014)

[11] Gaurav Chaudhary, Manoj kumar, Santosh Verma, Anupam Srivastav, " Optimization of drilling parameter of hybrid metal matrix composite using Response Methodology", Procedia Material Science, Vol.6, pp. 229-237 (2014)

[12]I. Nawi , W A Siswanto , A E Ismail “ A study of Auto pour in sand casting “ Applied Mechanics and Materials, Vol 660, pp74-78 (2014)

[13] S. Ranjan and S. Sridhar "Reaction of FeS with Simulated Slag and Atmosphere" American Chemical Society, Energy and Fuels (2011)

[14] N. Verma, W. Noh, M. Potter and P. C. Pistorius "Modification of Spinels in Liquid Steel" Proceedings of MS\&T Conference, Pittsburgh PA, pp. 189-197 (2010)

[15]Metin Kök, "Modeling the effect of surface roughness factors in the machining of 2024Al/Al2O3 particle composites based on orthogonal arrays" Volume:55, No:2, PP.911-920 (2010) 